\title{
Las estadísticas Oficiales de Turismo: Principales lagunas en el contexto nacional e internacional
}

\author{
FERNANDO CORTINA GARCIA
}

Subdirector General de Estadísticas de Empresas del Instituto Nacional de Estadística, ESPAÑA. E-mail: fcortina@ine.es

\section{RESUMEN}

En el ámbito de las estadísticas de turismo se han producido notables desarrollos en los últimos años, tanto por parte del sector público como del privado. El actual sistema de estadísticas oficiales de turismo en España se puede considerar como uno de los más desarrollados en el contexto internacional pero todavía persisten importantes lagunas de información. La comparabilidad de resultados precisa de una mayor armonización metodológica puesto que cada país decide las fuentes de información y metodologías a desarrollar para dar cumplimiento a la normativa comunitaria.

Palabras clave: Estadística oficial, comparabilidad internacional, armonización metodológica.

\section{Official Statistics of Tourism: Major Gaps in the National and International Context}

\begin{abstract}
In the field of tourism statistics have been remarkable developments in recent years by both the public and private sectors. The current system of official statistics on tourism in Spain can be considered as one of the most developed in the international context but there are still important gaps in information. The comparability of results requires greater harmonization methodology since each country decides the sources of information and methodologies to be developed to comply with Community law.
\end{abstract}

Keywords: Official Statistic, International Comparability, Methodological Harmonisation.

Clasificación JEL: C10

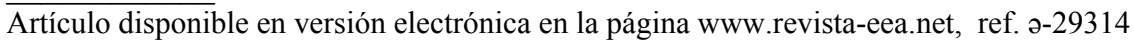




\section{INTRODUCCIÓN}

Para poder valorar si un sistema de estadísticas satisface los requisitos de calidad y las demandas de información de los usuarios a los que están dirigidas, el Comité del Programa Estadístico de la Unión Europea adoptó el 24 de febrero de 2005 el "Código de buenas prácticas de las estadísticas europeas" publicado en la Recomendación de la Comisión, de 25 de mayo de 2005, sobre la independencia y la responsabilidad de las autoridades estadísticas nacionales y comunitarias.

Los gobiernos y autoridades estadísticas de la Unión Europea se comprometen a respetar los principios establecidos en el presente Código y a revisar su aplicación periódicamente utilizando los indicadores de buenas prácticas correspondientes a cada uno de los quince principios, relativos al entorno institucional, a los procesos estadísticos y a la producción estadística, que deberán utilizarse como referencia.

En lo que se refiere a la producción estadística, el Código establece que las estadísticas disponibles deben satisfacer las necesidades de los distintos usuarios, es decir, las necesidades de las instituciones europeas, los gobiernos, los organismos de investigación, las empresas y el público en general.

Los principales requisitos que deben cumplir las estadísticas es que sean pertinentes, precisas, fiables, oportunas, coherentes, comparables entre regiones y países, y de fácil acceso para los usuarios.

Una vez tenido en cuenta los criterios que las estadísticas deben satisfacer, habría que definir qué se entiende por "estadísticas oficiales". Para ello, tomaremos como referencia la práctica de algunos países, dado que no existe una definición armonizada y que pudiera dar lugar a un consenso internacional.

En el caso de México, para que una operación estadística se considere oficial debe "satisfacer los siguientes requisitos:

Debe corresponder temáticamente a uno de los subsistemas de información nacional:

- Se debe elaborar con una metodología científicamente sustentada.

- Debe ser generada en forma regular y periódica.

- Su finalidad debe ser la de ser útil para la toma de decisiones, el diseño, la implementación y la evaluación de políticas públicas para el desarrollo del país,

la cual será oficial y de uso obligatorio para la Federación, los estados, el Distrito Federal y los municipios."

En el caso del Reino Unido, la acreditación como "Estadísticas Nacionales" significa que dichas estadísticas se consideran compatibles con el Código de Prácticas para las estadísticas oficiales, publicadas por la Autoridad en enero de 
2009. La Autoridad Estadística tiene la obligación de evaluar todas las estadísticas nacionales existentes para determinar si la designación debe continuar.

En el caso de España, las estadísticas oficiales son aquellas que son producidas por algún organismo público, de la Administración Central o Autonómica generalmente, si bien también pueden intervenir otros organismos de entidad privada. Habitualmente estas estadísticas figuran en el Plan Estadístico Nacional aunque no siempre sucede así.

Una vez que se ha enmarcado el estudio y los criterios que ha de reunir un sistema de estadísticas oficiales de turismo, a continuación se analizarán las principales demandas de información del actual sistema de estadísticas de turismo para el caso de España, resaltando las carencias y lagunas actuales más importantes, a nivel nacional e internacional así como la evolución de este último.

\section{PRINCIPALES DEMANDAS DE INFORMACIÓN NACIONALES EN MATERIA DE ESTADÍSTICAS OFICIALES DE TURISMO}

A lo largo del primer semestre de 2011 se llevó a cabo una consulta estructurada a los principales usuarios de las estadísticas oficiales con carácter general. Fueron consultados diferentes departamentos ministeriales, organismos estadísticos de las comunidades autónomas, cámaras de comercio, asociaciones empresariales, etc., con el fin de evaluar las diferentes carencias y bondades del actual sistema de estadísticas, dedicando un capítulo temático al turismo.

En esta consulta se pusieron de manifiesto una serie de carencias y necesidades de información, entre las que cabe destacar las siguientes:

- Disponer de una operación estadística que facilite información sobre el gasto turístico de los residentes (identificando el gasto en transporte internacional) en sus viajes al exterior de forma similar a la que proporciona la Encuesta de Gasto Turístico (EGATUR) relativa al gasto turístico de los no residentes en sus viajes a nuestro país.

- Proporcionar información sobre el alojamiento privado de uso turístico en España desde el punto de vista de las unidades que proporcionan este tipo de servicio y su impacto en términos económicos.

- Proporcionar información del excursionismo, evaluando el atractivo de los diferentes recursos turísticos así como los elementos determinantes de la elección de los destinos por parte de los turistas (tanto para el excursionismo como para los turistas).

- Ampliar la información disponible sobre el excursionismo tanto en la faceta del turismo receptor como en el interno. 
- Proporcionar información sobre la sostenibilidad ambiental en los principales destinos turísticos.

- Estudiar la posible homogeneización de las mediciones del gasto turístico receptor e interno.

- Difundir información de un Índice de Precios Turísticos a partir de la información que facilita el Índice de Precios de Servicios.

- Difundir información para determinados segmentos dentro de las actividades turísticas: agentes mayoristas y minoristas, oferta complementaria: comercio, servicios, ocio, etc., aparte del hospedaje, parques naturales, monumentos turísticos, etc.

- Recortar los plazos de difusión, en cuanto a la información relativa al turismo se refiere, de las Encuestas de Hogares que facilitan este tipo de información (Encuesta de Presupuesto Familiares y FAMILITUR fundamentalmente).

- Recortar los plazos de difusión de las distintas operaciones estadísticas, entre ellas la Cuenta Satélite de Turismo, o bien facilitar indicadores adelantados.

Si bien es cierto que en los últimos años se han producido avances importantes relacionados con el turismo, y que España puede considerarse como uno de los países que más estadísticas oficiales de turismo desarrolla, aún existen numerosas lagunas de información, como ya se ha puesto de manifiesto anteriormente, relacionadas con el turismo. Ahora bien, si se comparase esta situación con la de otros países de nuestro entorno veríamos que son muy similares.

Por otra parte, es cierto que en España la industria turística representa aproximadamente el $11 \%$ del PIB, lo que justifica que en nuestro país se destinen más recursos para obtener información que en otros países como Alemania donde el turismo se analiza más desde una óptica de mercado emisor.

De hecho, además de las demandas de información citadas anteriormente, el sector privado ha manifestado la necesidad de disponer no sólo de indicadores y operaciones estadísticas que faciliten información sobre variables físicas (pernoctaciones) o sociodemográficas (comportamiento) o económicas, de un periodo de tiempo relativamente reciente, sino también indicadores que permitan predecir el futuro (por ejemplo la ocupación, o la afluencia de turistas en el próximo verano o en determinadas temporadas puntuales como Semana Santa, etc.).

Centrándonos en las carencias o lagunas de información identificadas anteriormente, por su importancia y trascendencia en el análisis del turismo se pueden resaltar las siguientes:

- El alojamiento privado de uso turístico 
- El excursionismo

- El desfase entre la información disponible y el período de referencia.

Dado que el excursionismo y el desfase de la información son temas que se abordarán cuando se trate la nueva reglamentación europea, a continuación se analizará más detenidamente el alojamiento privado de uso turístico

\section{EL ALOJAMIENTO PRIVADO DE USO TURÍSTICO: LA PRINCIPAL LAGUNA DE NUESTRO ACTUAL SISTEMA DE ESTADÍSTICAS DE TURISMO}

Se puede afirmar que en España se disponen de estadísticas de calidad tanto de oferta como de demanda, que permiten cuantificar el alojamiento reglado en establecimientos colectivos. No ocurre lo mismo con el alojamiento privado, que se analiza solamente desde la perspectiva de las estadísticas demanda, y no desde el punto de vista de la oferta. Esto impide disponer de un buen contraste de la información y una visión completa del sector que permita cuantificar el número de viviendas, su distribución, su uso y, en definitiva su impacto económico.

Las estadísticas de demanda muestran un incremento del turismo residencial, tanto de residentes como de no residentes. Según las encuestas de frontera, cerca de una tercera parte de los turistas no residentes que llegan a España se alojan en viviendas de su propiedad, alquiladas o de familiares y amigos. Este porcentaje ha ido creciendo en los últimos años gracias, entre otras razones, al desarrollo de las compañías aéreas de bajo coste y las posibilidades que las nuevas tecnologías brindan para contratar servicios turísticos. Para el turismo residente, según la encuesta FAMILITUR, cerca de dos terceras partes de los viajes realizados por los residentes dentro de España utiliza el alojamiento privado como tipo de alojamiento.

Además el comportamiento de los turistas es diferente dependiendo del tipo de alojamiento elegido. Existen otros estudios que muestran que la aportación económica de los diferentes tipos de alojamiento es también muy distinta, no sólo por los efectos directos en la economía, si no también por los indirectos, en términos de empleo y riqueza que generan.

Además, hay que tener en cuenta los problemas urbanísticos y medioambientales que puede generar el fuerte crecimiento en las últimas décadas del número de viviendas en el litoral español.

En consecuencia, y con el fin de disponer de información sobre los aspectos anteriormente relacionados, sería deseable cuantificar el alojamiento privado de uso turístico desde el punto de vista de la oferta. Por lo tanto sería necesario conocer el número de alojamientos de potencial uso turístico y sus características (tamaño, número de habitaciones, número de plazas...), y su uso (quién las 
utiliza, durante cuanto tiempo, el motivo de ese uso...), y por último, el impacto económico.

Uno de los problemas con los que nos encontramos a la hora de analizar el alojamiento privado de uso turístico es el derivado de su definición. La normativa comunitaria define el alojamiento turístico como cualquier estructura empresarial que presta un servicio de alojamiento regularmente. Se distingue entre alojamiento colectivo y privado.

En concreto, se define alojamiento colectivo como aquel que ejerce una actividad comercial regular, consistente en ofrecer al turista la posibilidad de pernoctar en una habitación u otro espacio acondicionado para el alojamiento, siendo su capacidad mayor a un determinado número de camas. Por exclusión, el alojamiento privado, es aquel que no es ofrecido por una empresa y que tiene una capacidad limitada.

La Decisión de la Comisión relativa a las Estadísticas de Turismo alude a la dificultad que en algunos casos entraña clasificar determinados tipos de alojamiento como colectivos o privados. En concreto, se establece un doble criterio de clasificación:

- el desarrollo de una actividad económica de carácter comercial

- la capacidad de los establecimientos.

Los establecimientos de turismo rural y agroturismo, albergues, refugios de montaña y granja-escuelas, son claros ejemplos del ejercicio de actividades comerciales equiparables a las que desarrollan las empresas, si bien muchos de estos establecimientos no disponen de un determinado número de habitaciones o plazas, por lo que si se empleara el criterio de capacidad deberían ser considerados como alojamiento privado.

En el caso del INE de España se ha optado por dar preferencia a la tipología de la actividad que ejercen los establecimientos, considerando como alojamientos colectivos todos aquellos que cumplen una doble condición, con independencia del número de habitaciones o plazas que dispongan:

- Figuran en los directorios de las Consejerías de Turismo de las Comunidades Autónomas y están sometidos a la normativa vigente.

- Ejercen como actividad el alojamiento turístico.

En Austria, por ejemplo, se emplea el criterio de capacidad, de tal forma que cualquier establecimiento con una capacidad inferior a 9 plazas se considera alojamiento privado independientemente de si lleva a cabo una actividad comercial.

Una vez analizados los problemas de comparabilidad que plantea la definición de alojamiento privado de uso turístico se trataría de determinar el número de segundas viviendas de uso turístico. 
Para ello, el instrumento estadístico de mayor cobertura a la hora de recoger información es un Censo. En 2001 el INE llevó a cabo el Censo de Población y Viviendas. Como resultado, y dependiendo del uso que se hizo de ellas, las viviendas fueron clasificadas de la siguiente manera:

- Viviendas principales: cuando se trata de la vivienda principal de al menos una persona.

- Viviendas no principales: en esta categoría se distinguen las siguientes subclases:

- Viviendas secundarias: la vivienda se usa solamente para vacaciones, fines de semana, trabajos eventuales...

- Viviendas vacías: disponibles para alquiler o venta, o simplemente vacías.

- Otro tipo: por ejemplo, viviendas destinadas al alquiler durante cortos períodos de tiempo.

- Viviendas no principales sin determinar.

Como se puede observar no existe una categoría específica que permita diferenciar el número de viviendas de uso turístico. La siguiente tabla muestra los resultados del Censo de 2001:

Tabla 1

Censo de viviendas 2001

\begin{tabular}{lrrrr}
\hline \multicolumn{1}{c}{$\begin{array}{c}\text { Comunidad } \\
\text { Autónoma }\end{array}$} & \multicolumn{1}{c}{$\begin{array}{c}\text { Total } \\
\text { Viviendas }\end{array}$} & $\begin{array}{c}\text { Viviendas } \\
\text { Principales }\end{array}$ & $\begin{array}{c}\text { Viviendas } \\
\text { Secundarias }\end{array}$ & Viviendas Vacías \\
\hline Andalucía & 3.531 .124 & 2.415 .143 & 514.178 & 548.699 \\
Aragón & 654.483 & 443.205 & 117.980 & 85.716 \\
P. de Asturias & 523.616 & 389.310 & 55.699 & 72.640 \\
Islas Baleares & 501.840 & 305.431 & 97.148 & 85.535 \\
Canarias & 851.463 & 552.351 & 120.332 & 138.892 \\
Cantabria & 284.235 & 182.645 & 52.536 & 36.518 \\
Castilla y León & 1.449 .415 & 889.197 & 333.214 & 209.006 \\
Castilla-La Mancha & 986.051 & 610.227 & 229.424 & 137.900 \\
Cataluña & 3.314 .155 & 2.315 .774 & 514.943 & 452.921 \\
C. Valenciana & 2.547 .775 & 1.492 .744 & 564.086 & 444.823 \\
Extremadura & 573.796 & 366.893 & 96.785 & 103.506 \\
Galicia & 1.308 .363 & 900.376 & 166.711 & 229.360 \\
C. de Madrid & 2.478 .145 & 1.873 .671 & 275.705 & 306.556 \\
R. de Murcia & 592.613 & 378.211 & 111.431 & 95.589 \\
C. F. De Navarra & 258.721 & 188.730 & 31.080 & 35.102 \\
\hline
\end{tabular}


Tabla 1 (continuación)

Censo de viviendas 2001

\begin{tabular}{lrrrr}
\hline $\begin{array}{c}\text { Comunidad } \\
\text { Autónoma }\end{array}$ & \multicolumn{1}{c}{$\begin{array}{c}\text { Total } \\
\text { Viviendas }\end{array}$} & $\begin{array}{c}\text { Viviendas } \\
\text { Principales }\end{array}$ & $\begin{array}{l}\text { Viviendas } \\
\text { Secundarias }\end{array}$ & Viviendas Vacías \\
\hline País Vasco & 889.560 & 741.399 & 47.863 & 94.287 \\
La Rioja & 155.931 & 101.439 & 30.202 & 22.898 \\
Ceuta & 22.776 & 19.397 & 509 & 2.817 \\
Melilla & 22.492 & 17.833 & 805 & 3.687 \\
Total & $\mathbf{2 0 . 9 4 6 . 5 5 4}$ & $\mathbf{1 4 . 1 8 4 . 0 2 6}$ & $\mathbf{3 . 3 6 0 . 6 3 1}$ & $\mathbf{3 . 1 0 6 . 4 2 2}$ \\
\hline
\end{tabular}

Fuente: INE

En el siguiente mapa de España están representados el porcentaje de viviendas secundarias y vacías sobre el total de viviendas de cada comunidad autónoma, donde se puede apreciar que las CC.AA. con mayor proporción de viviendas secundarias y/o vacías son Comunidad Valenciana, Castilla y León, Castilla-La Mancha e Islas Baleares:

Figura 1

Viviendas secundarias vacias sobre el total de viviendas

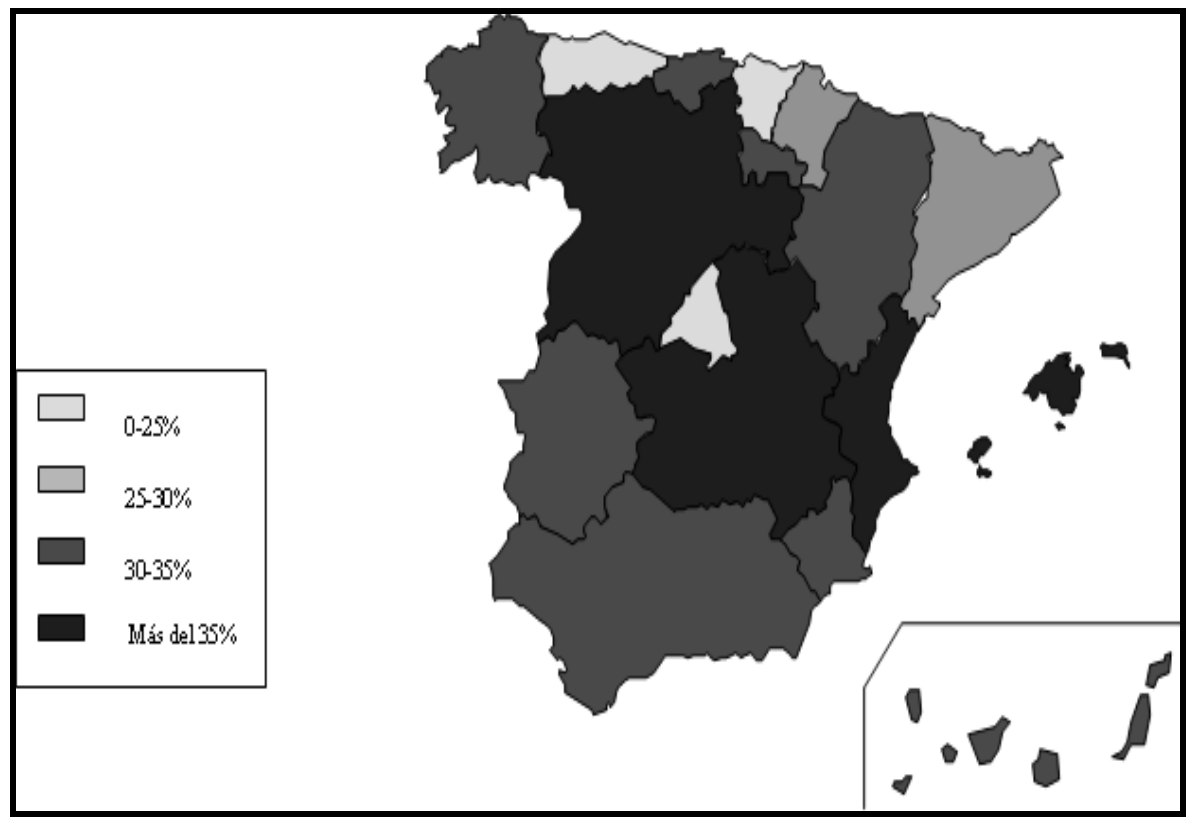

Fuente: Elaboración propia. 
Para analizar el alojamiento privado, el grupo de viviendas que se han de estudiar es el formado por las secundarias y las vacías (6.467.053 viviendas, $30,9 \%$ del total de viviendas registradas en España en 2001). Este nuevo conjunto constituirían lo que se denomina viviendas privadas de potencial uso turístico (se excluirían las viviendas principales que ceden temporalmente algunos meses o parcialmente alguna habitación para usos turísticos aunque a la hora de evaluar el impacto económico habría que tenerlas en cuenta).

La información censal actualizada sobre estas viviendas no se tendrá hasta que no estén disponibles los resultados del Censo de Población y Vivienda de 2011 que se está desarrollando actualmente. Un periodo demasiado amplio sin información sobre un fenómeno tan dinámico en el tiempo como es el turismo. En cualquier caso, el nuevo Censo tampoco permitirá diferenciar o cuantificar de forma directa el número de segundas viviendas de uso turístico.

Para suplir este vacío, a lo largo de estos años, y como método de aproximación, se pueden combinar dos registros administrativos, el Catastro y el Padrón Municipal de Habitantes, siendo:

- Catastro: registro administrativo en el que figuran todos los bienes inmuebles existentes en España y sus propietarios. Incluye también características físicas, económicas y legales. Por ejemplo, dónde están localizados, la referencia catastral y el propietario. La referencia catastral es el código oficial que identifica cada inmueble.

- Padrón Municipal de Habitantes: registro administrativo municipal que registra a la población residente en ese municipio. Contiene además información sobre la dirección postal completa de cada persona registrada.

Cruzando ambos registros por vivienda, se obtendría un subconjunto del Catastro formado por las viviendas en las que no hay personas empadronadas. Basándonos en el supuesto de que los habitantes han de estar empadronados en la vivienda donde residen habitualmente, se dispondría de un marco actualizado de viviendas secundarias y vacías, que constituye la población objeto de estudio del alojamiento privado de uso turístico.

Este cruce teórico conlleva diversas complicaciones a la hora de ponerlo en práctica, debido principalmente a la distinta naturaleza de ambos registros, tratándose el primero de bienes inmuebles y el segundo de personas.

Por otro lado, lo realmente interesante no es sólo conocer la oferta de este tipo de alojamiento turístico, sino también saber quién lo utiliza, cuándo y cuánto tiempo y por qué. Una vez determinada la población, habría por tanto que llevar a cabo una encuesta dirigida a los propietarios de estas viviendas, preguntándoles por las cuestiones antes planteadas y de este modo completar la investigación sobre el alojamiento privado de uso turístico desde el lado de la oferta, en España. 
Existen otros factores, como las viviendas propiedad de no residentes, muchas de ellas constituyen segundas viviendas de uso turístico, pero para las cuales resulta aún más complicado obtener información, por la dificultad de encontrar al titular puesto que unicamente pudiera ser cuando se encuentre habitando la vivienda (este colectivo quedaría fuera de una investigación dirigida a los hogares). Por lo que podemos concluir que todavía nos encontramos lejos de poder disponer de un marco actualizado de segundas viviendas de uso turístico.

No obstante, en algunas Comunidades Autónomas, y para determinados puntos o municipios turísticos, se han llevado a cabo "barridos de campo" para determinar sobre el terreno el número de segundas viviendas con uso turístico. Este método, aunque resulta costoso, sin duda permite disponer de información precisa y cuantificar el número de viviendas de uso turístico de dichos municipios.

\section{EVALUACIÓN DEL SISTEMA INTERNACIONAL DE ESTADÍSTICAS DE TURISMO: ARMONIZACIÓN A NIVEL DE OUTPUT PERO NO DE LAS METODOLOGÍAS SOBRE LAS QUE SE BASAN}

A nivel internacional, desde el año 1995 existe una Directiva de Turismo que obliga a los estados miembros de la Unión Europea a facilitar información armonizada y comparable relativa al turismo. Esta Directiva regula las variables, sus desgloses, la periodicidad y el desfase con el que cada país debe transmitir la información.

La experiencia de más de diez años trabajando con la Directiva del Consejo sobre Estadísticas de Turismo (95/57/EC) ha mostrado la solidez, pero también algunos problemas y debilidades, del actual sistema de las estadísticas comunitarias.

En particular, la comparabilidad y exhaustividad de los datos no son satisfactorias. Además, esta evaluación fue confirmada en un inventario sobre los métodos de recogida de datos sobre turismo, llevada a cabo en los Estados Miembros a mediados de 2006.

Fundamentalmente se comprobó que la comparabilidad de los datos estaba minada por diferentes motivos. Por ejemplo, uno de los sectores más desarrollados en cuanto a investigación se refiere es el sector del alojamiento colectivo, y más concretamente el sector hotelero. Sin embargo, las encuestas a hoteles presentan características que las hacen difícilmente comparables. Entre otras por las siguientes razones: 
- Las metodologías que desarrollan los países son muy heterogéneas, no sólo los tamaños de la muestra investigada sino los cuestionarios, o los períodos de investigación.

- Desviaciones en la cobertura: esto es la clasificación de actividad que se emplea no siempre considera las mismas modalidades de alojamiento colectivos.

- Uso de diferentes umbrales en los Estados Miembros a la hora de incluir las unidades que son objeto de investigación.

- Diferentes unidades estadísticas: La unidad estadística que emplean los distintos Estados Miembros a la hora de recoger la información no está armonizada. Esto afecta negativamente a la comparabilidad de los resultados entre países.

Respecto a los umbrales, algunos países aplican umbrales u otras limitaciones a la hora de incluir o no establecimientos en las encuestas. Algunas de esos umbrales están vinculados a las plazas o habitaciones del establecimiento, o a una combinación de ambas. Esto implica que un gran número de establecimientos pequeños quedan fuera del estudio, perdiendo información. Además la definición del umbral es distinta de un país a otro.

Por otro lado hay países que no utilizan umbrales, pero vinculan sus marcos a registros administrativos, desconociendo el criterio de inclusión a dichos registros.

Esto afecta a la calidad de los datos de dos maneras. La exhaustividad se reduce considerablemente, ya que existe una parte significativa del alojamiento que no se estudia. Por otro lado, la comparabilidad de los resultados entre países está viciada por este hecho.

Eurostat ha propuesto introducir un umbral consensuado entre los Estados Miembros a partir del cual se debe recoger información. Este umbral en el nuevo Reglamento se ha establecido en diez camas, por lo que de cara al futuro este problema se puede decir que ya se ha resuelto.

En lo que a la unidad estadística se refiere, Eurostat, en el reglamento recientemente aprobado se especifica que la unidad de recogida es la Unidad de Actividad Económica a nivel local (UAE local) ${ }^{1}$

Esta decisión es importante ya que los servicios de alojamiento se desarrollan, a veces, como la actividad secundaria de un establecimiento (por ejemplo,

\footnotetext{
${ }^{1}$ Según el Reglamento del Consejo (EEC) $n^{\circ}$ 696/93, se define la UAE a nivel local como la unidad que agrupa las partes de una empresa que desarrollan una misma actividad a nivel de clase y que corresponde a una o más subdivisiones operacionales de la empresa, sita en un lugar delimitado topográficamente.
} 
en el caso de hoteles es posible que el mayor porcentaje de valor añadido esté producido por los servicios de restauración).

Por todo ello, se puede deducir que aunque el Reglamento especifica y detalla perfectamente las variables que son objeto de transmisión, su desglose, la periodicidad de las mismas, no existe una armonización del input o de la metodología desarrollada por parte de los países. Si bien, como se ha comentado anteriormente en el caso del umbral se han producido avances importantes en aras de lograr una mayor comparabilidad.

Efectivamente, el nuevo Reglamento dedica un Anexo para el Turismo Interior, (Anexo I), y un Anexo para el Turismo Nacional (Anexo II). En ambos se detallan las variables, desgloses y la periodicidad de cada variable, pero cada país puede optar por la metodología que considere idónea.

Adicionalmente, han surgido nuevos elementos de interés político relacionados con el turismo, los cuales no están cubiertos por la directiva en vigor como puede ser el tema de la accesibilidad de las personas con problemas de movilidad.

\section{EVOLUCIÓN DEL SISTEMA DE ESTADÍSTICAS DE TURISMO EN EL ÁMBITO INTERNACIONAL: NUEVO REGLAMENTO SOBRE ESTADÍSTICAS DE TURISMO}

Hace apenas tres años, Eurostat comenzó los trabajos oportunos para actualizar la legislación europea en materia de estadísticas de turismo, culminando en el presente año 2011 con la aprobación del REGLAMENTO (UE) $\mathrm{N}$ o 692/2011 DEL PARLAMENTO EUROPEO Y DEL CONSEJO de 6 de julio de 2011 relativo a las estadísticas europeas sobre el turismo y por el que se deroga la Directiva 95/57/CE del Consejo.

Las principales novedades que contempla este Reglamento, en lo que a las lagunas y carencias de información a las que hemos hecho referencia, son las siguientes:

- Reducir los plazos de trasmisión de las estadísticas.

- Proporcionar indicadores rápidos o adelantados.

- Excursionismo.

\subsection{Reducir los plazos de trasmisión de las estadísticas}

La rapidez con la que están disponibles los resultados es un punto a tener en cuenta cuando se mide la calidad de una estadística. En el campo del turismo, siendo éste un fenómeno con fuertes fluctuaciones estacionales, más todavía y los usuarios de estos datos, como políticos y empresarios, deben reaccionar rápido ante los cambios. 
En el futuro reglamento se va a eliminar la distinción actual de resultados provisionales y definitivos. Se mantienen los plazos de transmisión de los actuales datos provisionales, es decir, los datos mensuales tres meses después del mes de referencia y los anuales, seis meses después de finalizar el año.

\subsection{Indicadores rápidos o adelantados}

Se puede considerar que esperar tres meses para conocer los datos mensuales es un lapso largo de tiempo y que dificulta la toma de decisiones tanto para los políticos como empresarios o usuarios de la información en general.. Por lo que se ha acordado que se incluyan en la legislación un conjunto de indicadores rápidos, disponibles ocho semanas después de finalizar el mes de referencia.

Estos indicadores son:

- Pernoctaciones de residentes en Hoteles y alojamientos similares.

- Pernoctaciones de residentes en Alojamiento turísticos y otros alojamientos de corta estancia.

- Pernoctaciones de residentes en Campings.

- Pernoctaciones de no residentes en Hoteles y alojamientos similares.

- Pernoctaciones de no residentes en Alojamiento turísticos y otros alojamientos de corta estancia.

- Pernoctaciones de no residentes en Campings.

\subsection{Excursionismo}

En el nuevo Reglamento se incluye para el turismo nacional un apartado dedicado a la información procedente de las excursiones.

Este hecho supone un avance importante puesto que todos los países están obligados a facilitar información sobre las excursiones, tanto al extranjero como a nivel interno del país, así como del gasto efectuado en las mismas.

Asimismo, aunque con carácter opcional, la información de las excursiones se debe facilitar desglosada por sexo, grupo de edad, nivel educativo, situación laboral, nivel de ingresos del hogar, país de destino y categoría de gasto.

No obstante, y dado el período transitorio que conceden los reglamentos, en el mejor de los casos dispondremos de información sobre el excursionismo para todos los países de la Unión Europea a partir de Enero de 2014 para las excursiones al extranjero, y a partir de enero de 2015 para las excursiones a nivel interno. 


\section{CONCLUSIONES}

El turismo es un sector que a nivel nacional se puede considerar privilegiado en cuanto a la investigación estadística que recibe pero todavía perduran campos y temas que constituyen importantes lagunas de información. Las segundas viviendas de uso turístico, el comportamiento y la estructura de gasto de los residentes en sus viajes al exterior, el excursionismo y el impacto de los diferentes destinos turísticos, son áreas en las que no existe información o bien, si existe, ésta resulta insuficiente para facilitar la toma de decisiones.

El nuevo Reglamento Europeo de Estadísticas de Turismo ha permitido avanzar y mejorar la comparabilidad internacional pero no garantiza el desarrollo de sistemas de estadísticas de turismo nacionales que garanticen la exhaustividad y completitud del sistema. Algunas de las lagunas citadas anteriormente no serán cubiertas por la nueva reglamentación comunitaria.

Tampoco el Censo de población y Viviendas 2011 resolverá el problema de la cuantificación del número de segundas viviendas de uso turístico, por lo que se podría decir que se ha dejado pasar una oportunidad histórica para arrojar más luz sobre este importante fenómeno.

Por otra parte, el sector privado demanda información e indicadores que permitan predecir las temporadas turísticas y no sólo ofrezcan información sobre el pasado aunque sea relativamente reciente.

Este último aspecto, los indicadores sobre las temporadas venideras, fundamental para la toma de decisiones empresariales, tampoco se ha contemplado en la normativa comunitaria que regula las estadísticas oficiales de turismo a nivel internacional.

\section{REFERENCIAS BIBLIOGRÁFICAS}

INE (2001). Metodología del Censo de Población y Viviendas de 2001. Madrid: INE.

UNIÓN EUROPEA (1999). Decisión (1999/35/CE) de la Comisión de 9 de Diciembre de 1998 sobre los procedimientos de aplicación de la Directiva 95/57/CE del Consejo sobre la recogida de información estadística en el ámbito del turismo. $D O \mathrm{~N}^{\circ} \mathrm{L} 9$ de 15.1.1999, p.:23.

UNIÓN EUROPEA (1995). Directiva 95/57/CE del Consejo de 23 de Noviembre de 1995 sobre el procedimiento de recogida de información estadística en el ámbito del turismo. $D O \mathrm{~N}^{\circ} \mathrm{L} 291$ de 6.12.1995, p.:32.

UNIÓN EUROPEA (2011). Reglamento (UE) N ó 692/2011 del Parlamento Europeo y del Consejo de 6 de julio de 2011 relativo a las estadísticas euro- 
peas sobre el turismo y por el que se deroga la Directiva 95/57/CE del Consejo. DO N L 192 de 22.7.2011, p.:17. 
